\title{
Shear resistance and cracking behaviour of SFRC beams with and without axial load
}

\author{
Yining DING ${ }^{\mathrm{a}}$, Hekai $\mathrm{LIU}^{\mathrm{b}}$, Yulin ZHANG ${ }^{\mathrm{c}}$, Xiliang NING ${ }^{\mathrm{a}}$ and Cecília AZEVEDO ${ }^{\mathrm{c}}$ \\ ${ }^{a}$ State Key Laboratory of Coastal and Offshore Engineering, DUT, Dalian \\ ${ }^{\mathrm{b}}$ Lvshun Administration of Urban and Rural Construction \\ ${ }^{\mathrm{c}}$ Centre of Mathematics, University of Minho 4700-052, Portugal
}

\begin{abstract}
In order to simulate and evaluate the fiber effect and the synergetic effect of the hybrid using of fibers and stirrups on the flexural shear resistance and diagonal cracking behavior of tunnel segment, a series experiments has been conducted. Different from the conventional testing method, the symmetric inclined beams subjected to combined action of flexure, shear and axial compression were used for simulating of the loading condition of the tunnel segment. The results indicated that steel fibers can enhance the ultimate shear resistance greatly, reduce the strain of tension steel, decrease the diagonal crack width; and the combined use of steel fibers and stirrups shows a significant positive composite effect on the load carrying capacity and the failure pattern of the symmetric inclination beams. The addition of $50 \mathrm{~kg} / \mathrm{m}^{3}$ steel fibers can transform the brittle diagonal shear failure pattern of RC beams into a ductile flexural failure pattern.
\end{abstract}

Keywords: Symmetric inclination beam; steel fiber; shear resistance; crack behavior and failure pattern 


\section{Introduction}

Regarding the stress state of tunnel segment, one of the major differences between the conventional simply supported (SS) beam and tunnel segment is the presence of compressive force. Even so, the SS beam (Fig. 1a) has been often used to characterize the bending behaviour of SFRC or to analyze the section of the tunnel segment [1-2] without considering of the axial compressive action in the tunnel segment. Until now, the experimental results for beams subjected to combined effect of bending, shear and compression are still very rare. Moreover, the limited data [3] were adopted the beam with exerting axial force by jack at each end (Fig.1b). There would be some shortages of this method: a) the constant axial force exerted by jack cannot reflect the loading condition of tunnel segment in practice, because the compressive force on the section of the tunnel segment changes with the changing of the rock pressure; b) the segments with different central angle and curvature cannot be simulated by simply supported beam.

a)

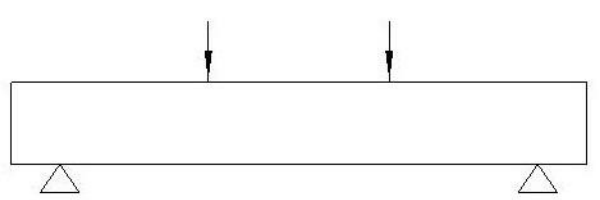

b)

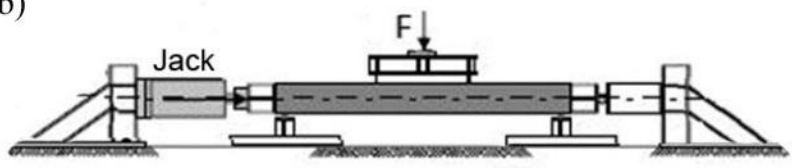

Figure 1 Conventional test method: a) Simply supported beam and b) Simply supported beam with jack

In order to avoid the shortages above mentioned, a new test method called symmetric inclination (SI) beam (Fig.2) [4-5] was suggested for investigation of the effect of compressive force and steel fiber on the load carrying capacity and crack resistance of tunnel segment, however, only few experimental studies were carried out. The characteristic of SI beam was using inclined 
support (Fig.2) instead of vertical one. The two supports were fixed on testing machine, guarantied no shift between them. Compared with conventional method using SS beam (Fig.1), this method introduces an inclined support reaction (Fig. 2) with compressive force, which can enhance flexural and shear capacity, reduce the crack width and crack spacing and well used for simulating the loading condition of tunnel segment (Fig. 3).

a)

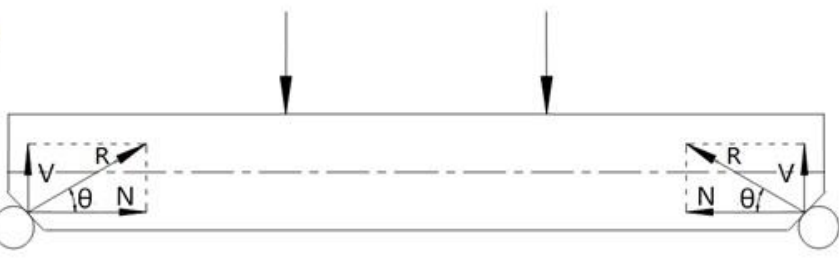

b)

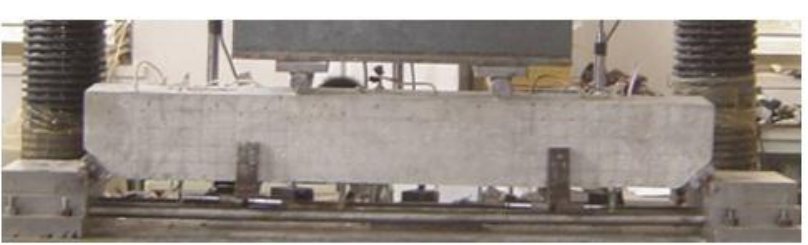

Figure 2 a) Inclined Supported beam, b) Testing setup

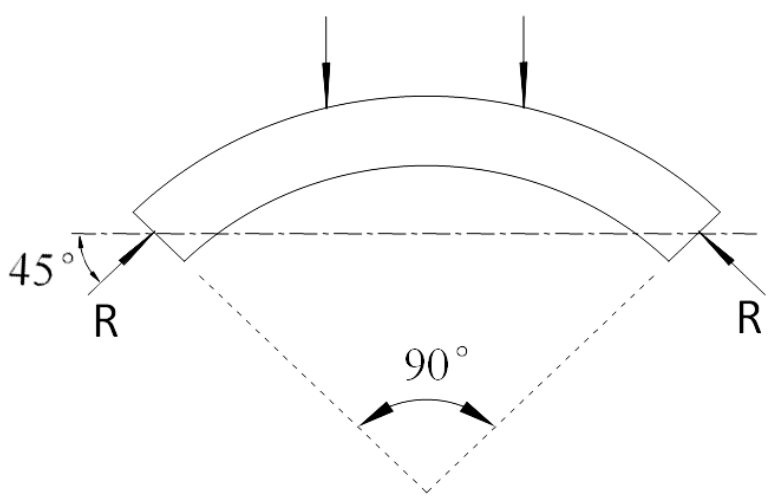

Figure 3 Tunnel segment with $90^{\circ}$ central angle

The inclined compression was quite significant in the enhancement of load bearing capacity of SI beam as compared to SS beams. While it is hard to specify quantitatively the exact equivalent range regarding SS beam (Fig.1), SI beam (Fig.2) and tunnel segment (Fig.3), based on the 
available information [4-7], SI beams with compression induced by the inclined support are more suitable and rational to simulate the loading state of tunnel segment qualitatively. The SI beam can be also cheap and easy to produce because the full scale test of tunnel segment is difficult and very expansive. In this work, an inclination of $45^{\circ}$ was selected for simulating the segment with $90^{\circ}$ central angle (Fig.3).

Steel fibers have been largely adopted in tunnel linings, as shown by several precast structural steel fiber reinforced concrete (SFRC) tunnel segments [8]. There is a growing interest in tunnel segments, where structure fibers could partial replace the conventional steel rebars [9]. The steel rebars, the thickness and the cost of tunnel segment can be considerably reduced due to the presence of structural fibers $[4-5,8,10]$.

The using of steel fiber reinforced concrete (SFRC) in the manufacturing of tunnel segment may show various advantages [1]. The fiber reinforcement improves the performance of concrete under tension, greatly increasing the toughness, the fatigue and the impact resistance $[2,11]$. The steel fiber orientation plays an important role for the effectiveness, because the fibers are distributed three dimensional in the tunnel segment and many fibers can be orientated along the trajectories of principal tensile stress.

Previous studies $[10,12-15]$ on structural applications of SFRC beams, with or without transverse steel, have shown the effect of fiber reinforcement. Since steel fibers are well distributed in tunnel segment, the fibers can also reduce the spacing error of stirrups, bridge cracks and limit the crack width; the crack width should be smaller than that of conventional RC tunnel segment $[6,16]$. Steel fibre addition in the concrete tunnel segment brings a better control of its cracking and improves its mechanical properties, imparts to concrete a post peak load carrying 
capacity, which decreases its fragile character of tunnel.

Compared with conventional reinforced concrete, another advantage of SFRC is its corrosion resistance and improved durability [17-19]. Steel fibers can be filled into the un-reinforced regions of tunnel segment and prevent local damage like abrasion, spalling or chipping of tunnel corners [1, 20-23] due to the improved impact resistance.

The objectives of tunnel segment using steel fiber reinforcement include a number of issues such as the water permeability, fire resistance, resistance to carbonation, impact resistance and fatigue resistance, cracking pattern, material properties and failure mode etc. However, it is not intended in this study to present a complete knowledge of every aspect of steel fiber in steel reinforced SI beam or tunnel segment. Among the numerous issues, as well known that the sudden brittle failure of diagonal flexural shear crack is not allowed for RC member and tunnel segment, so it is important to know a) if steel fibers can mitigate the diagonal shear crack, or even to change the failure pattern from sudden brittle shear failure into a ductile flexural failure of SI beam with compression; and b) how many stirrups can be replaced by steel fibers in the SI beams under combined action of bending, shear and compression force. Hence, the focus is given to 1) investigating the mechanical behaviour of tunnel segment using SI beam and 2) analyzing the hybrid effect of fiber and steel reinforcement on the load carrying capacity, on the crack and failure pattern of reinforced SI beam.

\section{Experimental program}

\subsection{Materials}

The designed compressive strength of the plain concrete was $60 \mathrm{MPa}$ and the mixture proportion 
is given in Table 1.

Table 1 Mixture proportion of base matrix $\left(\mathrm{kg} / \mathrm{m}^{3}\right)$

\begin{tabular}{lcccccc}
\hline $\begin{array}{l}\text { Cement } \\
(\mathrm{C})\end{array}$ & $\begin{array}{c}\text { Fly ash } \\
\text { (FA) }\end{array}$ & $\begin{array}{c}\text { Binder } \\
(\mathrm{B})\end{array}$ & $\begin{array}{c}\text { Fine aggregate } \\
(0-5 \mathrm{~mm})\end{array}$ & $\begin{array}{c}\text { Coarse aggregate } \\
(5-10 \mathrm{~mm})\end{array}$ & $\begin{array}{c}\text { Water } \\
(\mathrm{W})\end{array}$ & $\begin{array}{c}\text { Superplasticizer } \\
(\mathrm{SP})\end{array}$ \\
\hline 390 & 150 & 440 & 808 & 808 & 178 & 9.72 \\
\hline
\end{tabular}

The concrete was made with PO. I 42.5R Portland cement and fly ash. The coarse aggregates were crushed gravel and had a specific weight of $2630 \mathrm{~kg} / \mathrm{m}^{3}$, with the particle size between 5 and 10 $\mathrm{mm}$. The fine aggregates were natural river sand and had a fineness modulus of 2.6, with the particle size of 0 - $5 \mathrm{~mm}$. The steel fiber was RC-65/35-BN (Fig.4): fiber length $\mathrm{L}_{\mathrm{f}}=35 \mathrm{~mm}$; equivalent diameter $D_{f}=0.55 \mathrm{~mm}$ (aspect ratio $L_{f} / D_{f}=65$ ), the fibre number per kg was 14,500 pieces $/ \mathrm{kg}$; nominal tensile strength $\mathrm{ff}=1150 \mathrm{~N} / \mathrm{mm}^{2}$. The nominal diameter of the tension steel (Fig.5) for all beams was $14 \mathrm{~mm}$, the diameter of the stirrups (Fig.6) was $6.5 \mathrm{~mm}$, and the diameter of tie steel was $8 \mathrm{~mm}$. The tension steel rebars, stirrups and tie steel had a yielding strength of $490 \mathrm{~N} / \mathrm{mm}^{2}$ and $290 \mathrm{~N} / \mathrm{mm}^{2}$ respectively, and they had an ultimate stress of $690 \mathrm{~N} / \mathrm{mm}^{2}$ and $430 \mathrm{~N} / \mathrm{mm}^{2}$, respectively; which were in accordance with the requirements of Chinese Code for design of concrete structures [24].

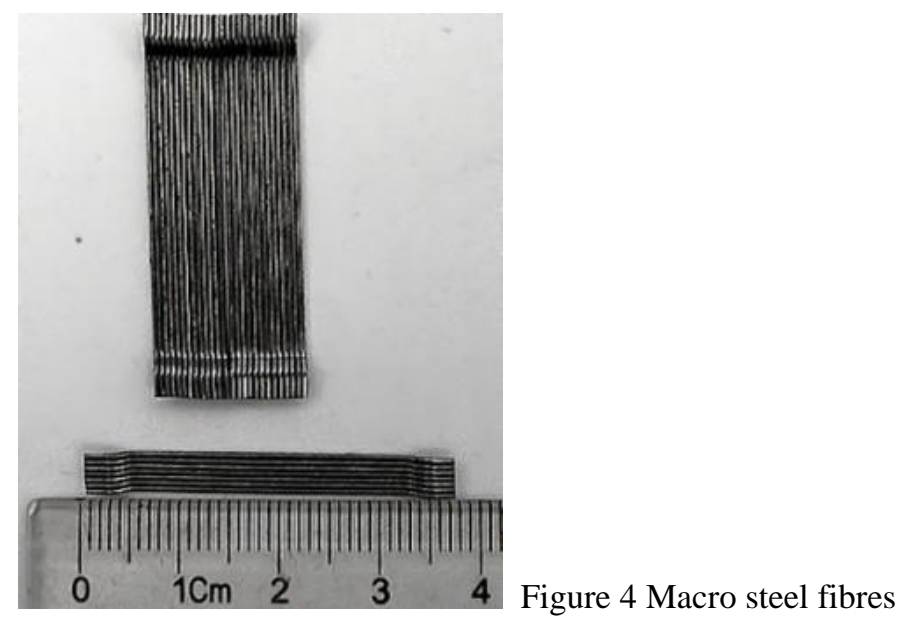




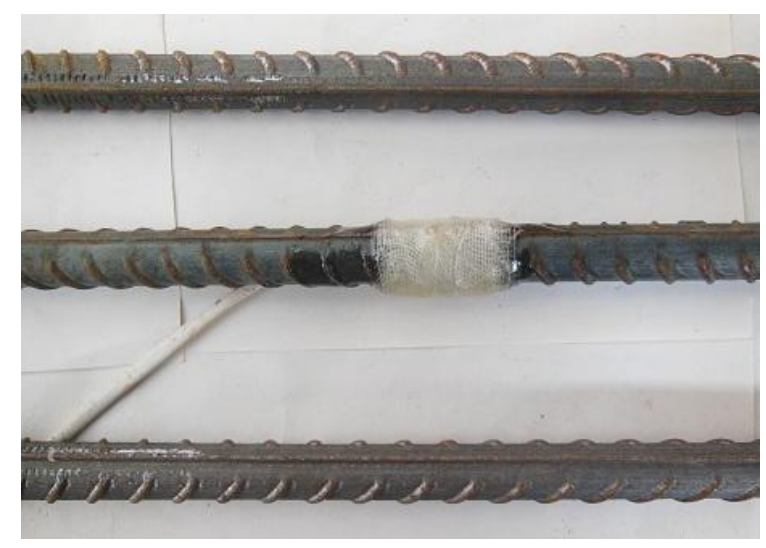

Figure 5 Conventional longitudinal rebars

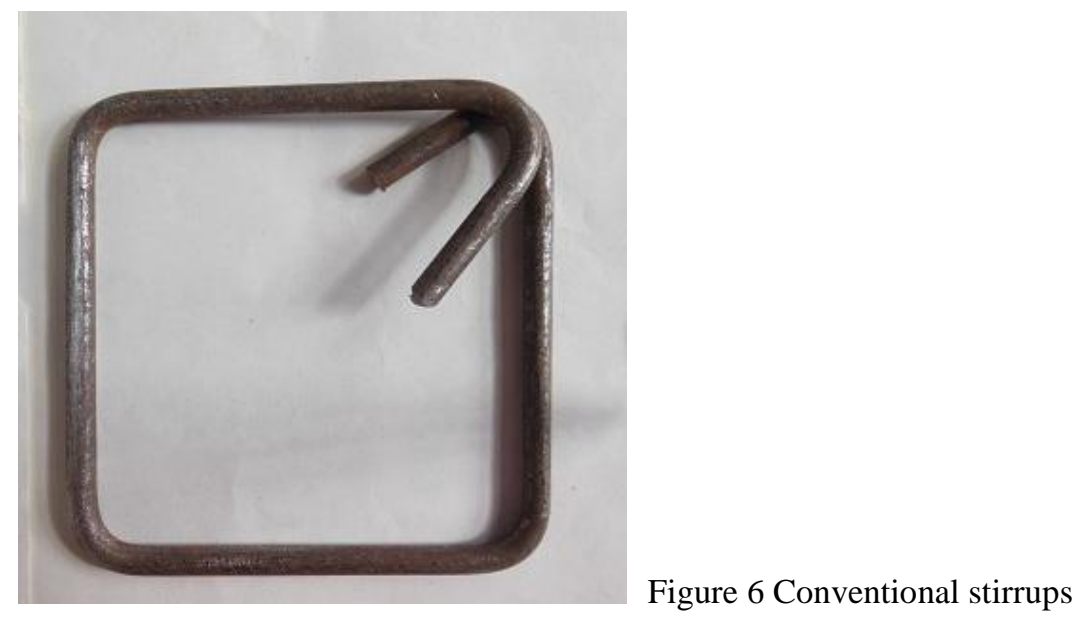

2.2 Fiber influence on the strength and toughness of concrete

The cubic specimens of $150 \mathrm{~mm} \times 150 \mathrm{~mm} \times 150 \mathrm{~mm}$ were used to determine the compressive strength $\left(f_{c u}\right)$. The test results of cubic compressive strength at $28 \mathrm{~d}$ are listed in Table 2.

Table 2 Fiber effect on the compression strength, flexural strength, energy absorption and equivalent flexural strength of specimens

\begin{tabular}{lcccccc}
\hline & $\mathrm{f}_{\mathrm{cu}}(\mathrm{Mpa})$ & $\mathrm{f}_{\mathrm{L}}$ & $\mathrm{D}_{\mathrm{f} 2}$ & $\mathrm{D}_{\mathrm{f} 3}$ & $\mathrm{f}_{\mathrm{eq} 2}$ & $\mathrm{f}_{\mathrm{eq} 3}$ \\
\hline SF0 & 60.5 & 4.43 & & & & \\
\hline SF25 & 61.4 & 4.86 & 6.67 & 31.29 & 4.27 & 4.01 \\
\hline SF50 & 60.2 & 5.79 & 13.86 & 52.77 & 8.87 & 6.75 \\
\hline
\end{tabular}


The addition of steel fiber aims in converting the properties of brittle concrete into a ductile material [22], however no significant trend of improvement in compressive strength was observed. According to RILEM [25] in the three-point flexural test, the dimension of flexural specimen was $150 \mathrm{~mm} \times 150 \mathrm{~mm} \times 550 \mathrm{~mm}$, tested on a span of $500 \mathrm{~mm}$ (Fig. 7).

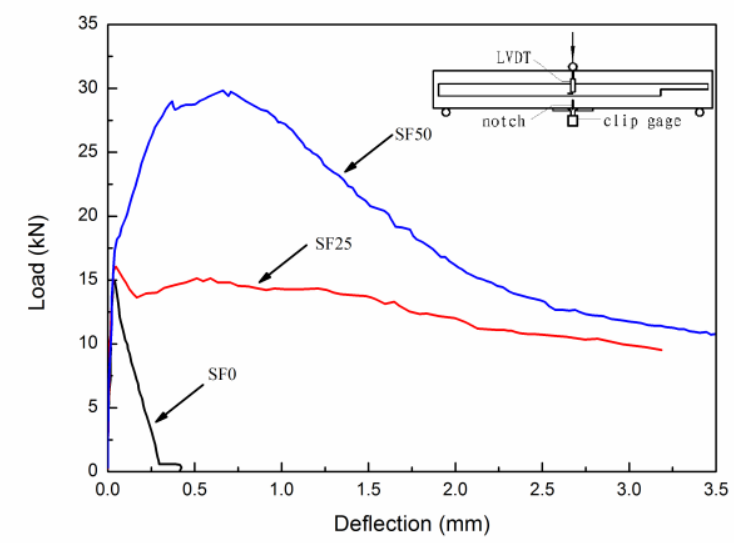

Figure 7. Comparison of load-deflection curves with different fibre contents (LVDT: linear variable differential transformer)

The loading rate was $0.2 \mathrm{~mm} / \mathrm{min}$, the load-deflection curves are evaluated up to a beam deflection of $3.0 \mathrm{~mm}$. The comparison of load-deflection curves of concrete bending samples with steel fibre contents of $0 \mathrm{~kg} / \mathrm{m}^{3}$ (SF0), $25 \mathrm{~kg} / \mathrm{m}^{3}$ (SF25) and $50 \mathrm{~kg} / \mathrm{m}^{3}$ (SF50) after 28 days is illustrated in Fig.7. It can be seen that:

- The flexural strength of specimens increases slightly with the increasing of fiber dosage.

- The flexural specimen of SF0 without steel fibres does not show any toughness, after the first crack the load bearing capacity fell down abruptly.

- Compared to SF0 without steel fibres, the post crack behaviour of SF25 increased greatly

- Compared to SF25, SF50 with $50 \mathrm{~kg} / \mathrm{m}^{3}$ steel fibres indicated a much better energy absorption ability after the first crack than SF25 over the entire deflection range and showed 
a deflection- hardening behavior under flexure.

The comparison of the mean values of the flexural strength (fL) and post-crack parameters (The energy absorption $D_{\mathrm{f} 2}$ and $\mathrm{D}_{\mathrm{f}}$, equivalent flexural strength parameters: feq,2, feq,3) for SF0, SF25 and SF50 according to the RILEM [25] are listed in Table 2. It can be seen that: 1) Fibres demonstrate strong influence on the flexural toughness with the increasing of fibre dosages. 2) Compared to SF0, flexural strength of SF25 changed about 9.8\%. 3) Compared to SF25, the energy absorption $\left(\mathrm{D}_{\mathrm{f} 2}, \mathrm{D}_{\mathrm{f} 3}\right)$ and equivalent flexural strength (feq2, feq3) of SF50 increased by about $108 \%$ and $69 \%$, respectively. Furthermore, it has been observed that flexural failure pattern of the specimens changed from only one major crack for SF0 and SF25 into a multiple crack pattern of SF50. This means that the tensile stress distributed more uniformly in the SF50.

\subsection{Tested bending members}

The test program included 36 concrete bending members. The member geometry, reinforcement arrangement, the loading and supporting schemes are demonstrated in Fig.8.

a)

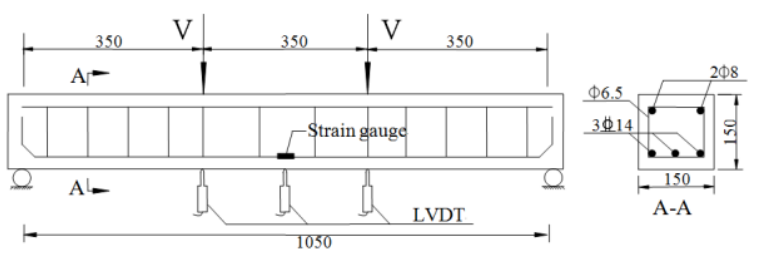

b)

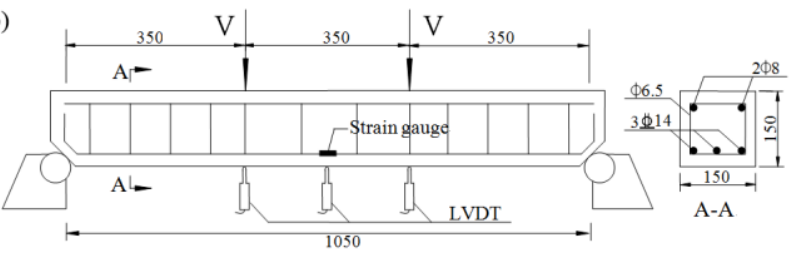

Figure 8. (a) SS (simply supported) beam; (b) IS (inclined support) beam 
a) Critical diagonal crack (Brittle

failure with large crack width)

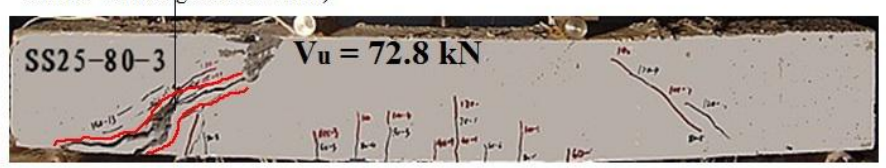

b)

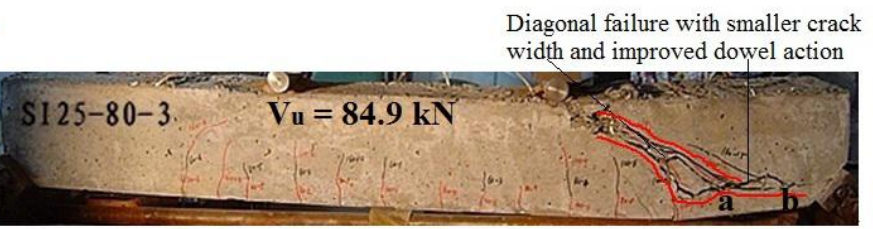

Figure 9 Comparison of crack pattern and failure mode of IS beams and SS beams: a) SS beams with

$25 \mathrm{~kg} / \mathrm{m}^{3}$ steel fibres and b) IS beams with $25 \mathrm{~kg} / \mathrm{m}^{3}$ steel fibres

The dimension of the beam is B (width) $\mathrm{x} \mathrm{H}$ (depth) $\mathrm{x} \mathrm{L} \mathrm{(length)}=150 \times 150 \times 1100 \mathrm{~mm}$ with a constant shear span to effective depth ratio $(\mathrm{a} / \mathrm{d})$ of 3 , tested on a span Ls $=1050 \mathrm{~mm}$.

The first series of tested members were SS beams with a constant longitudinal reinforcement ratio $(2.6 \%)$ and stirrup ratio $(0.55 \%)$, but with different fiber contents $\left(0,25 \mathrm{~kg} / \mathrm{m}^{3}, 50 \mathrm{~kg} / \mathrm{m}^{3}\right)$. The other beams were SI beams. The variables distinguished among the SI beams were the amount of longitudinal steel ratio $(2.6 \%$ and $1.73 \%)$, stirrup ratio $(0,0.3 \%$ and $0.55 \%)$ and fiber content $\left(0,25 \mathrm{~kg} / \mathrm{m}^{3}, 50 \mathrm{~kg} / \mathrm{m}^{3}\right)$. The beams were designed by beam type, steel fiber content, stirrup spacing and longitudinal steel ratio. The beam designation included a combination of letters and figures: SS or SI indicates the beam type of simply supported beam or symmetric inclination beam; the first figure indicates fiber content; the next figure 80 or 150 denotes stirrup spacing; the last letter $\mathrm{A}$ or $\mathrm{C}$ indicates the longitudinal steel ratio of $2.6 \%$ or $1.73 \%$. For example, a symmetric inclination beam with stirrup spacing of $80 \mathrm{~mm}$, longitudinal reinforcement ratio of $2.6 \%$ and steel fiber content of $25 \mathrm{~kg} / \mathrm{m}^{3}$ is designated as SI-25-80-A (Table 3). 
Table 3 Details of test beams

\begin{tabular}{|c|c|c|c|c|c|c|}
\hline $\begin{array}{l}\text { Different } \\
\text { beams }\end{array}$ & $\begin{array}{c}\text { Fiber } \\
\text { dosage } \\
\left(\mathrm{kg} / \mathrm{m}^{3}\right)\end{array}$ & $\mathrm{a} / \mathrm{d}$ & $\begin{array}{l}\text { Stirrup } \\
\text { spacing } \\
(\mathrm{mm})\end{array}$ & $\begin{array}{c}\text { Stirrup ratio } \\
(\%)\end{array}$ & $\begin{array}{l}\text { Number of } \\
\text { longitudinal } \\
\text { steel bars }\end{array}$ & $\begin{array}{l}\text { longitudinal reinforcement } \\
\text { ratio } \\
(\%)\end{array}$ \\
\hline SS-0-80-A & 0 & 3 & 80 & 0.55 & $3 \not 14$ & 2.60 \\
\hline SS-25-80-A & 25 & 3 & 80 & 0.55 & $3 \not 14$ & 2.60 \\
\hline SS-50-80-A & 50 & 3 & 80 & 0.55 & $3 \not 14$ & 2.60 \\
\hline SI-0-80-A & 0 & 3 & 80 & 0.55 & $3 \not 14$ & 2.60 \\
\hline SI-25-80-A & 25 & 3 & 80 & 0.55 & $3 \not 14$ & 2.60 \\
\hline SI-50-80-A & 50 & 3 & 80 & 0.55 & $3 \not 14$ & 2.60 \\
\hline SI-25-150-A & 25 & 3 & 150 & 0.3 & $3 \not 14$ & 2.60 \\
\hline SI-50-150-A & 50 & 3 & 150 & 0.3 & $3 \not 14$ & 2.60 \\
\hline 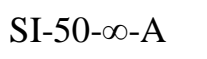 & 50 & 3 & $\infty$ & 0 & $3 \not 14$ & 2.60 \\
\hline SI-0-80-C & 0 & 3 & 80 & 0.55 & $2 \not 14$ & 1.73 \\
\hline SI-25-80-C & 25 & 3 & 80 & 0.55 & $2 \not 14$ & 1.73 \\
\hline SI-50-80-C & 50 & 3 & 80 & 0.55 & $2 \not 14$ & 1.73 \\
\hline
\end{tabular}

\subsection{Test set-up}

The beams were subjected to symmetrically concentrated four-point loading condition (see Fig.8). Three linear variable displacement transducers (LVDT) were placed directly under the mid-span and loading point of each beam to measure the deflection at mid-span and loading point. In order to analyze the fiber effect on the strain of longitudinal steel during the loading process, the electrical strain gauges were glued to the tension steel at mid-span. The test was conducted in $10000 \mathrm{kN}$ hydraulic servo testing machine. The close-loop test was deformation controlled with a deformation rate of $0.3 \mathrm{~mm} / \mathrm{min}$. During testing, the applied load, deflections at mid-span and loading points, the strains of longitudinal reinforcement at mid-span were recorded continuously until the mid-span deflection of tested beams reached $15 \mathrm{~mm}$. The developed cracks were marked on the beam face, and the maximum width of flexural crack and diagonal crack was measured and illustrated in Table 4. 
Table 4 Experimental results of test beams

\begin{tabular}{|c|c|c|c|c|c|c|}
\hline \multirow{2}{*}{$\begin{array}{l}\text { Average } \\
\text { value of three } \\
\text { beams }\end{array}$} & \multicolumn{3}{|c|}{ Applied load (kN) } & \multirow{2}{*}{$\begin{array}{l}\text { Failure } \\
\text { pattern }\end{array}$} & \multirow{2}{*}{$\begin{array}{l}\text { Maximum } \\
\text { crack width } \\
\quad(\mathrm{mm})\end{array}$} & \multirow{2}{*}{$\begin{array}{l}\text { Number } \\
\text { of crack } \\
\text { at failure }\end{array}$} \\
\hline & $\begin{array}{l}\text { At first } \\
\text { flexure } \\
\text { crack/ } V_{c f}\end{array}$ & $\begin{array}{c}\text { At first } \\
\text { diagonal } \\
\text { crack/ } V_{c d}\end{array}$ & $\begin{array}{c}\text { Ultimate } \\
\text { shear load } \\
\text { / } V_{u}\end{array}$ & & & \\
\hline SS-0-80-A & 6 & 15.4 & 57.8 & Shear & 1.94 & 9 \\
\hline SS-25-80-A & 7 & 17 & 72.8 & Shear & 1.24 & 12 \\
\hline SS-50-80-A & 8.4 & 30.2 & 86 & Flexural & 0.64 & 15 \\
\hline SI-0-80-A & 7.6 & 28.4 & 77.3 & Shear & 0.82 & 10 \\
\hline SI-25-80-A & 8.2 & 34.2 & 84.9 & Shear & 0.44 & 12 \\
\hline SI-50-80-A & 9.6 & 46.5 & 99.3 & Flexural & 0.34 & 16 \\
\hline SI-25-150-A & 8.3 & 32.2 & 77.6 & Shear & 0.42 & 14 \\
\hline SI-50-150-A & 8.4 & 39.2 & 90.4 & Shear & 0.3 & 18 \\
\hline 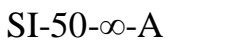 & 7.8 & 33.2 & 73.7 & Shear & 0.59 & 13 \\
\hline SI-0-80-C & 7.4 & 28.2 & 70.8 & Shear & 1.2 & 10 \\
\hline SI-25-80-C & 7.6 & 30.4 & 75.8 & Shear & 0.62 & 14 \\
\hline SI-50-80-C & 9.2 & 40.4 & 86.9 & Shear & 0.55 & 15 \\
\hline
\end{tabular}

3. Results and Discussion

\subsection{Crack pattern and failure mode}

The comparison of the crack pattern and failure mode between SS beams and SI beams with different fiber contents is demonstrated in Fig.9. From Fig. 9a) it can be seen that:

1) For the simply supported beam SS 25 without compression force, the first recordable flexural cracks occurred in the mid-span at early loading stage $\left(\mathrm{V}_{\mathrm{cf}}=7 \mathrm{kN}\right.$, see Table 4$)$. With the increasing of load, the beam showed fewer wider cracks $(0.4-0.7 \mathrm{~mm}$ see Fig. 9a) in the mid-span and relatively large crack spacing (about $5-6 \mathrm{~cm}$ ).

2) In the flexural shear region of beam $S S 25$, the first flexural shear crack formed at $V_{c d}$ (about 17 $\mathrm{kN}$ ), then the diagonal cracks appeared and propagated towards the loading point approximately along the trajectory of the principle compressive stress gradually. With further increasing of load, 
the existing cracks lengthened and widened. The large diagonal cracks developed in the similar direction as that of line between support and loading point. Some diagonal cracks joined to form the "critical diagonal crack" (about $1.2 \mathrm{~mm}$, see Fig. 9a). A slightly increase in V will cause the diagonal crack to penetrate into the compression zone at the loading point, until eventually crushing failure of the concrete occurs there. The section fails as the principal compression stress at the top of the diagonal crack exceeded the multiaxial strength subjected to the combined stress of shear and compression. For this failure pattern, the ultimate shear load $\mathrm{V}_{\mathrm{u}}$ was $72.8 \mathrm{kN}$ and about four times that $\mathrm{V}_{\mathrm{cd}}$ at first diagonal cracking.

3) It is desirable to ensure that the ultimate strength is governed by flexure rather than by shear. The diagonal shear failures, which in reality are failures under combined shear force and bending moment, are characterized by small deflections and lack of ductility. There is sometimes little warning before failure occurs, and this makes shear failures particularly dangerous.

4) For the symmetric inclination beam SI 25 with compression force from inclined support, the flexural cracks formed in the mid-span at loading stage of $\mathrm{V}_{\mathrm{cf}}=8.2 \mathrm{kN}$. With the increasing of load, due to the compressive force and the fiber effect, the beam showed some relatively thin cracks $(0.3-0.6 \mathrm{~mm})$ in the mid-span and smaller crack spacing (about 4-5 cm, Fig. $9 \mathrm{~b}$ ) compared to that of SS 25 beam.

5) In the flexural shear zone of symmetric inclination beam SI 25 with compressive force, the appearance of diagonal crack was restricted and delayed strongly by the inclined compression, e.g. the first diagonal crack formed at $\mathrm{V}_{\mathrm{cd}}=34.2 \mathrm{kN}$, it was more than twice that of the simply supported beam SS 25. The growth of the crack width was slower in SI beams than that in SS beams without compressive force. This may imply that: a) Due to the inclined compression force, 
the first diagonal cracking load of steel fiber reinforced tunnel segment can be much stronger than that of steel fiber reinforced simply supported beam; b) Using of the simply supported beam to analyze the tunnel segment section can be very conservative.

6) In the flexural shear zone of SI beam 25 , some cracks developed in the concrete around the longitudinal tension steel (see Fig. 9b)). As load V was further increased, the diagonal crack widened and propagated along the level of the tension steel (crack a-b). The increased shear force $\mathrm{V}$ pressed down the longitudinal steel and could cause the destruction of the bond between the concrete and the steel. Due to the bridging effect of fibers, the splitting of the concrete along a-b in the flexural shear region of the beam could be avoided. The dowel action on the longitudinal steel has been improved.

a)

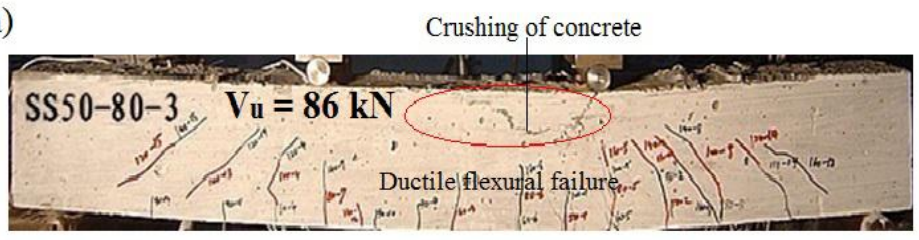

b)

Crushing of concrete

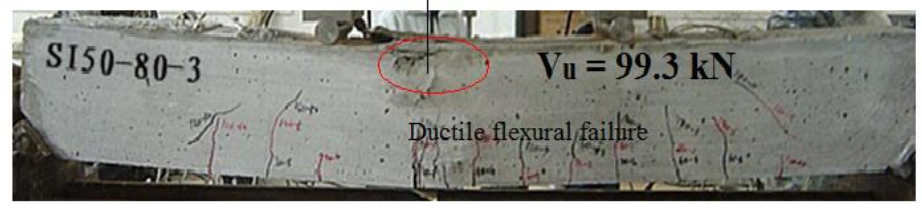

Figure 10 Comparison of crack pattern and failure mode of IS beams and SS beams: a) SS beams with $50 \mathrm{~kg} / \mathrm{m}^{3}$ steel fibres and b) IS beams with $50 \mathrm{~kg} / \mathrm{m}^{3}$ steel fibres 


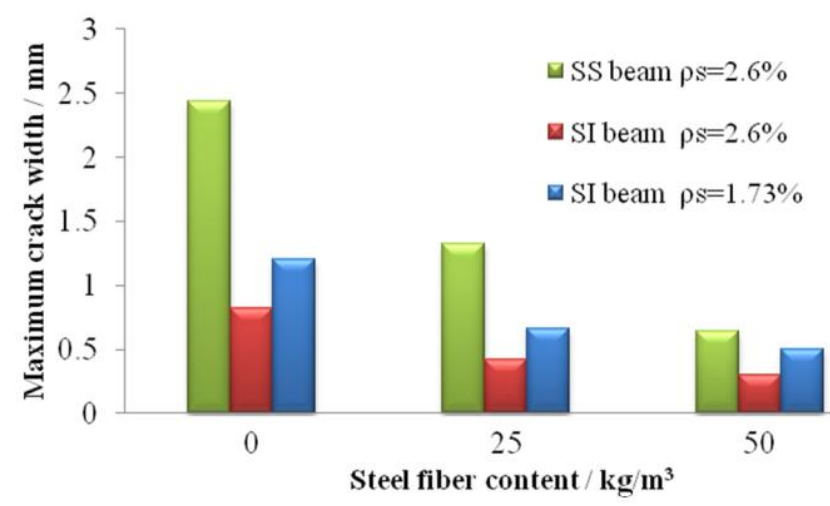

Figure 11 Comparisons of maximum crack width among beams with stirrup ratio of $0.55 \%$

From Fig.10a) and Fig.10b) it can be seen that:

1) Compared to simply supported beam (SS 25 in Fig.9a)) with beams of increasing fiber content (SS 50), the loads at the first flexural crack $\left(\mathrm{V}_{\mathrm{cf}}\right)$, the first diagonal crack $\left(\mathrm{V}_{\mathrm{cd}}\right)$ and the ultimate load $\left(\mathrm{V}_{\mathrm{u}}\right)$ of SS 50 increased $20 \%, 70 \%$ and $18 \%$, respectively.

2) Compared to simply supported beam SS 50 in Fig.10a), and due to the compression of the inclined support, the $\mathrm{V}_{\mathrm{cf}}, \mathrm{V}_{\mathrm{cd}}$ and $\mathrm{V}_{\mathrm{u}}$ of $\mathrm{SI} 50$ increased $14 \%, 49 \%$ and $17 \%$, respectively.

3) More important is that the collapse of beams SI 50 and SS 50 was mainly the crushing of the concrete in the compression zone of the beam top at mid span. There was only small or insignificant diagonal cracks observed in beams SI 50 or SS 50. Both beam SS 50 and beam SI 50 demonstrated a flexural failure with relatively large deformation of mid span compared to that of beam SS 25 and SI 25.

4) The addition of $50 \mathrm{~kg} / \mathrm{m}^{3}$ steel fibre could transform the brittle diagonal shear failure of SS 25 and SI 25 into a ductile flexure failure pattern of beam SS 50 and beam SI 50 (Fig. 10a)) and Fig. 10b)). It means that $50 \mathrm{~kg} / \mathrm{m}^{3}$ steel fibres have a clear effect on the failure pattern and deformability of the RC beam. The ductility of such a beam provides ample warning of impending failure. 
The comparison of average results of the loading behaviour, cracking property and failure pattern of all the SS and SI beams with different fiber contents are listed in Table 4. The comparisons of the influence of different longitudinal steel ratios $(\rho s)$ on the maximum crack width of beams with constant stirrup ratio of $0.55 \%$ are illustrated in Fig. 11. The hybrid effect of the combined use of stirrups and steel fibers on the crack width is demonstrated in Fig. 12.

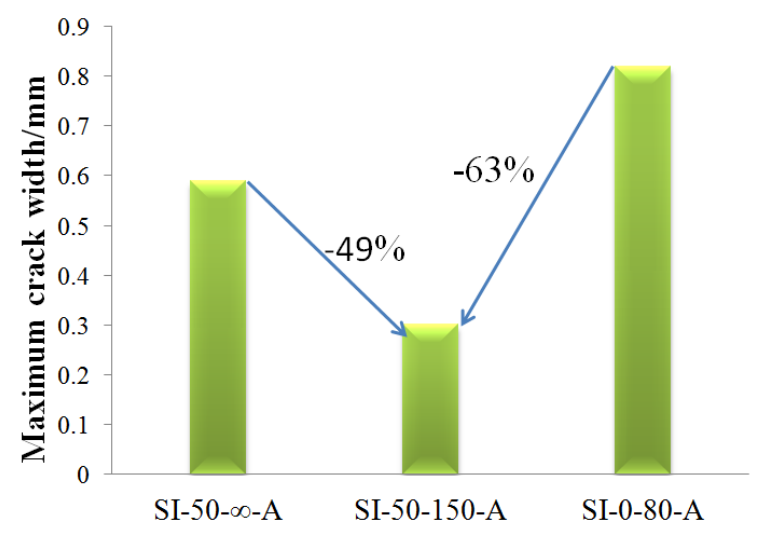

Figure 12 Positive synergetic effect of steel fibres and stirrups on reducing of the crack width
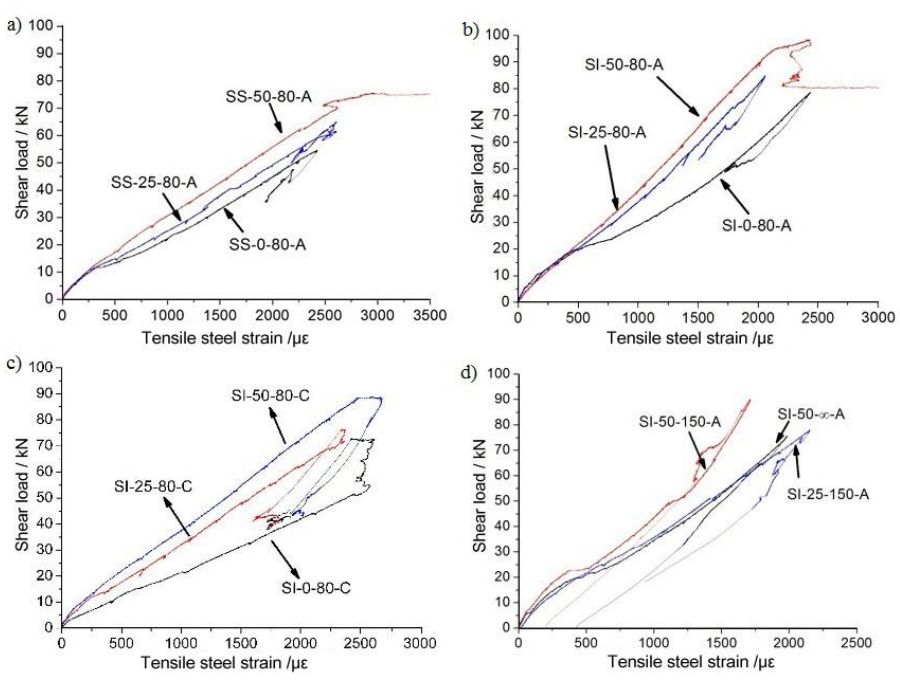

Figure 13 Fibre influence on strain of longitudinal rebars of: a) Load - strain curves of SS beams $\left(\rho_{\mathrm{s}}=\right.$ $2.6 \%)$; b) Load - strain curves of IS beams $\left(\rho_{\mathrm{s}}=2.6 \%\right)$; c) Load - strain curves of IS beams $\left(\rho_{\mathrm{s}}=\right.$ 
$1.73 \%)$; d) Load - strain curves of IS beams with different stirrup spacing $\left(\rho_{\mathrm{s}}=2.6 \%\right)$ and fibre dosages

From Table 4, Fig. 11 and Fig. 12, it can be seen that

1) The first flexural cracking load varied between $9.7 \%$ and $10.4 \%$ of the ultimate load $V_{u}$. For SS beams, the first diagonal cracking load varied between $20.4 \%$ and $35 \%$ of $\mathrm{V}_{\mathrm{u}}$. For SI beams, the first diagonal cracking load varied between $37 \%$ and $47 \%$ of $\mathrm{V}_{\mathrm{u}}$ due to the inclined compression.

2) Both for SS beam and SI beam, the first diagonal cracking load increased with the increasing of the fiber content.

3) SI beams exhibited less diagonal crack number and crack width (Fig. 11) compared with SS beams. This may be attributed to the action of the compressive force induced by the inclined support reaction.

4) Steel fibers can restrict the widening and progress of the diagonal shear cracks and reduce spalling of concrete. With the increasing of fiber content, the maximum diagonal crack width decreased clearly, e.g. the crack widths of beams SI-25-80-A and SI-50-80-A were reduced by $46 \%$ and $59 \%$, compared to beams without fibers (SI-0-80-A), respectively. This could be traced back to the larger number of fibers crossing the cracks.

5) The beams with lower tension steel ratio ( $\rho s=1.73 \%$, e.g. beams SI-0-80-C, SI-25-80-C and SI-50-80-C) showed larger crack widths than that with higher tension steel ratio $(\rho s=2.6 \%$, see Fig. 11), because the low tension steel ratio led to a larger deflection at the same loading level.

6) The arrangement of more stirrups in beams also reduced the diagonal crack width. However, a combination of steel fibers and stirrups showed clear positive synergetic effect on reducing of the crack width, the maximum diagonal crack width of beam SI-50-150-A decreased by $63 \%$ and $49 \%$

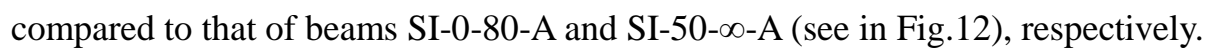


7) All beams without fibers and with only $25 \mathrm{~kg} / \mathrm{m}^{3}$ steel fibers failed in diagonal shear. The combined use of $50 \mathrm{~kg} / \mathrm{m}^{3}$ steel fibers and stirrups with ratio of $0.55 \%$ could transform the brittle diagonal shear failure into a more ductile flexural failure of the beams.

\subsection{Effect of steel fibers on shear load carrying capacity}

The effect of steel fibers on the strain of longitudinal rebars is illustrated in Fig.13. Fig. 13a) shows the comparison of effect of different fiber dosages on the load - strain relationships of tension rebar of SS beams ( $\rho s=2.6 \%$ ). Fig. 13b) shows the comparison of effect of different fiber dosages on the load - strain relationships of tension steel of SI (symmetric inclination) beams ( $\rho_{\mathrm{s}}$ $=2.6 \%)$. Fig. 13c) shows the comparison of effect of different fiber dosages on the load - strain relationships of tension steel of SI beams with low steel ratio $\left(\rho_{\mathrm{s}}=1.73 \%\right)$. For SS beam in Fig.13a), when fiber content increased from $25 \mathrm{~kg} / \mathrm{m}^{3}$ up to $50 \mathrm{~kg} / \mathrm{m}^{3}$, the strains of longitudinal steel decreased from $9 \%$ up to $19 \%$ in the post-cracking stage at the same load level (e.g. $50 \mathrm{kN}$ ), because the steel fibers crossing the cracks could partially take up the tension and restrict the widening of cracks. Furthermore, for SI beam in Fig.13b), the strains of longitudinal steel decreased between $35 \%$ and $44 \%$ with the increasing of the fiber contents at the loading level of $50 \mathrm{kN}$ due to the combined effect of the inclined compression and the steel fibers. It means that the steel strain of tunnel segment could be reduced clearly due to the combination of compression force and fibers.

The ultimate shear loads of all beams are summarized in Table 4 . The results indicate that the resistance of SI beam/tunnel segment can be increased strongly by addition of steel fiber and the inclined compression: 
- Compared with the SI beam without fibers (SI-0-80-A in Fig. 13b), the ultimate shear load $\left(\mathrm{V}_{\mathrm{u}}\right)$ of the beams with $25 \mathrm{~kg} / \mathrm{m}^{3}$ (SI-25-80-A) and $50 \mathrm{~kg} / \mathrm{m}^{3}$ steel fibers (SI-50-80-A) increased $10 \%$ and $28 \%$, respectively, when stirrup ratio maintained $0.55 \%$ (stirrup spacing of $80 \mathrm{~mm}$ ) and longitudinal steel ratio maintained $2.6 \%$.

- Compared with the SI beam with low steel ratio and without fibers (SI-0-80-C in Fig. 13c), $\mathrm{V}_{\mathrm{u}}$ of the beams with $25 \mathrm{~kg} / \mathrm{m}^{3}$ steel fibers (SI-25-80-C) and $50 \mathrm{~kg} / \mathrm{m}^{3}$ steel fibers (SI-50-80-C) increased about $7 \%$ and $22 \%$, respectively, when stirrup ratio maintained $0.55 \%$ and longitudinal steel ratio maintained $1.73 \%$.

- The ultimate shear load $\mathrm{V}_{\mathrm{u}}$ of beam SI-50-150-A was $16 \%$ higher than that of beam SI-25-150-A, when stirrup ratio maintained $0.3 \%$ (corresponding stirrup spacing of $150 \mathrm{~mm}$ in Fig. 13d) and longitudinal steel ratio maintained $2.6 \%$.

- Comparing Fig. 13a) and Fig, 13b), it can be seen that the strain of tension rebars of SI beams was much lower than that of SS beams at the same loading level (for instance at $50 \mathrm{kN}$ ), because the compression from the inclined support may confine the longitudinal deformation of beams. The average tension strain of longitudinal steel of SI beam declined about $35 \%$ compared to those of SS beams. It means that the compression force can enhance beam stiffness and improve the crack behavior of SI beam as well as tunnel segment.

\subsection{Possible replacement of stirrups by steel fibers}

As mentioned above, steel fibers could enhance the load carrying capacity obviously and act as effective shear reinforcement for both SI beams and SS beams. It means that steel fibers may partly replace the stirrups and is beneficial for tunnel segment. Some important points can be 
observed as follows:

1) Compared with beam SI-0-80-A without fibers (stirrup ratio $\rho_{\mathrm{v}}=0.55 \%$ ), the ultimate shear load $\mathrm{V}_{\mathrm{u}}$ of beam SI-50- $\infty-\mathrm{A}$ (with $50 \mathrm{~kg} / \mathrm{m}^{3}$ steel fibers, without stirrups, see Fig.13d) decreased by 4.7\%. It means that the shear reinforcement of $\varphi 6.5 @ 80$ (the diameter of the stirrups $=6.5 \mathrm{~mm}$, stirrup spacing $=80 \mathrm{~mm}$ ) in this study cannot be totally replaced by $50 \mathrm{~kg} / \mathrm{m}^{3}$ steel fibers.

2) Compared with beam SI-0-80-A ( $\rho_{v}=0.55 \%$, without fibers), $\mathrm{V}_{\mathrm{u}}$ of beam SI-25-150-A ( $\rho \mathrm{v}$ $=0.3 \%$, with $25 \mathrm{~kg} / \mathrm{m}^{3}$ steel fibers) is approximately equivalent; $\mathrm{V}_{\mathrm{u}}$ of beam SI-50-150-A (with $50 \mathrm{~kg} / \mathrm{m}^{3}$ steel fibers, $\rho_{\mathrm{v}}=0.3 \%$, stirrup spacing $=150 \mathrm{~mm}$ ) increased by $17 \%$, and the corresponding maximum crack width decreased by $49 \%$ and $63 \%$, respectively.

3) Compared with beam SI-50- $\infty$ A (with $50 \mathrm{~kg} / \mathrm{m}^{3}$ steel fibers, without stirrups, Fig.13d), $\mathrm{V}_{\mathrm{u}}$ of beam SI25-150-A ( $\rho_{\mathrm{v}}=0.3 \%$, with $25 \mathrm{~kg} / \mathrm{m}^{3}$ steel fibers) increased by $5.3 \%$ and the maximum crack width decreased by $29 \%$. It means that the load-carrying capacity and crack resistance of the SI beam with the hybrid use of stirrups and steel fibers are stronger than that of the beam with only shear or fiber reinforcement. The combination of stirrups and steel fibers shows a significant positive hybrid effect on enhancing the load-carrying capacity and reducing the maximum crack widths of symmetric inclination beams as well tunnel segment.

4) Compared with beam SI-25-80-A ( $\rho_{v}=0.55 \%$, with $25 \mathrm{~kg} / \mathrm{m}^{3}$ steel fibers, Fig. $\left.13 \mathrm{~b}\right), \mathrm{V}_{\mathrm{u}}$ of beam SI-50-150-A ( $\rho_{\mathrm{v}}=0.3 \%$, with $50 \mathrm{~kg} / \mathrm{m}^{3}$ steel fibers, Fig.13d) increased about $6.5 \%$ and the corresponding maximum crack width decreased about $31 \%$.

From the analysis above, it can be summarized that the addition of $25 \mathrm{~kg} / \mathrm{m}^{3}$ steel fibers can partially replace stirrups, reduce the stirrup ratio from $0.55 \%$ to $0.3 \%$, which means an enlargement of stirrup spacing from $80 \mathrm{~mm}$ to $150 \mathrm{~mm}$. It can be also beneficial for reducing of 
the construction period. Compared to the beam with only $25 \mathrm{~kg} / \mathrm{m}^{3}$ steel fibers, a significant hybrid effect of stirrups and $50 \mathrm{~kg} / \mathrm{m}^{3}$ steel fibers can be achieved.

\section{Conclusions}

It is important for better understanding of the fiber effect and hybrid effect of steel fiber and rebar on the shear properties, strain behavior and crack pattern of the symmetric inclination beam as well as tunnel segment under combined action of flexure, shear and compression force. The investigation showed that both the steel fiber content and inclined compression of support exert significant influences on the load bearing capacity and failure pattern of SI beam. Based on the results, the following conclusions can be drawn:

i) Due to the inclined compression, the first diagonal cracking load of SI beam was twice that of the SS beam 25. Using the SS beam to analyze the tunnel segment section is conservative.

ii) Steel fibers are effective in restricting diagonal shear cracks and preventing the sudden brittle failure. The bridging effect of steel fibers can prevent the splitting of the concrete and the destruction of the dowel action on the longitudinal steel of the SI beam/tunnel segment, and this effect increases with the increasing of fiber content.

iii) The combined using of stirrups and steel fibers demonstrated a strong positive hybrid effect on the ultimate shear load, on reducing steel strain and crack width of beams or tunnel segment under the combined action of flexure, shear and axial force.

iv) Compared with the beams without fibers, the presence of the inclined compression of SI beam can reduce the strains of longitudinal rebars between $18 \%$ and $40 \%$ in the post-cracking stage.

v) Compared with the SS beams without compressive force, the formation of diagonal crack of SI 
beams has been delayed greatly due to the compression induced by the inclined support. The inclined compressive force can enhance beam stiffness and improve the crack behavior of SI beam as well as tunnel segment.

vi) Compared with SI beams without steel fibers (SI-0-80-A), the maximum diagonal crack width of beams SI-25-80-A and SI-50-80-A declined $46 \%$ and 59\% with the increasing of fiber content, respectively.

vii) The addition of $50 \mathrm{~kg} / \mathrm{m}^{3}$ steel fibers can transform the brittle diagonal shear failure pattern of SS and SI beams with stirrup spacing of $80 \mathrm{~mm}$ into a ductile flexural failure pattern.

This work is the first step to study the symmetric inclination beam subjected to the combined action of compression, flexure and shear, in order to analyze the fiber influence on the crack pattern, failure mode and load bearing capacity of the tunnel segment.

The use of SI beam for simulating of the fiber reinforced tunnel segment has not yet been widely utilized due mainly to the lack of the experimental and theoretical comparison between the SI beam and tunnel segment. It deserves a number of thoughts for its comprehension and for investigation of suitable design. Our next step is to perform more experimental studies both on SI beam and tunnel segment in full scale with various steel ratios, steel fiber type and contents, and try to establish theoretical models. Based on the comparison of the mechanical properties between SI beam and tunnel segment, the relationships between fiber reinforced tunnel segment and SI beam with inclined compression and steel fiber content should be better explored.

\section{Notation}


SS simply supported beam

SI symmetric inclination beam

$\mathrm{L}_{\mathrm{f}} \quad$ steel fiber length

$\mathrm{D}_{\mathrm{f}} \quad$ equivalent diameter of steel fiber

$\mathrm{f}_{\mathrm{cu}} \quad$ compressive strength

SS-0-80-A simply supported beam without steel fibers, stirrup spacing $=80 \mathrm{~mm}$ and longitudinal reinforcement ratio $=2.6 \%$

SI-25-80-C symmetric inclination beam with $25 \mathrm{~kg} / \mathrm{m}^{3}$ steel fibers, stirrup spacing $=80 \mathrm{~mm}$ and longitudinal reinforcement ratio $=1.73 \%$

SI-25-150-A (stirrup ratio $\rho_{\mathrm{v}}=0.3 \%$, with $25 \mathrm{~kg} / \mathrm{m}^{3}$ steel fibers),

SI-50-150-A (Stirrup ratio $\rho_{\mathrm{v}}=0.3 \%$, with $50 \mathrm{~kg} / \mathrm{m}^{3}$ steel fibers)

$\mathrm{V}_{\mathrm{c}, \mathrm{f}} \quad$ Shear load at first flexure crack

$\mathrm{V}_{\mathrm{c}, \mathrm{d}} \quad$ Shear load at first diagonal crack

$\mathrm{V}_{\mathrm{u}} \quad$ Ultimate shear load

\section{Acknowledgements}

The authors acknowledge the National Natural Science Foundation of China (Grant: 50278013), the National Natural Science Foundation of China (Grant: 51121005), Fundação para a Ciência e a Tecnologia (SFRH/BPD/22680/2005), the FEDER Funds through "Programa Operacional Factores de Competitividade - COMPETE" and by Portuguese Funds through FCT - within the Projects PEst-OE/MAT/UI0013/2014 and PTDC/MAT/112273/2009. 
References

[1] Fuente d. 1. A., Pujadas P., Blanco A., Aguado A. (2012): Experiences in Barcelona with the use of fibres in segmental linings, Tunnelling and Underground Space Technology 27:

$60-71$.

[2] Caratelli A., Meda A., Rinaldi Z. and Romualdi P. (2011): Structural behaviour of precast tunnel segments in fiber reinforced concrete, Tunnelling and Underground Space Technology 26: 284-291.

[3] Haddadin M. J., Hong S.-T., and Mattock A. H. (1971). Stirrup Effectiveness in Reinforced Concrete Beams with Axial Force. Journal of the Structural Division 97: 2277-2297.

[4] Feyerabend B. (1995). "Zum Einfluss verschiedener Stahlfasern auf das Verformungs und Rissverhalten von Stahlfaserbeton unter den Belastungsbdingungen einer Tunnelschale." RUHR Universitaet Bochum Institut fuer Konstruktiven Ingenieurbau, Mitteilung Nr. 95-8.

[5] Hemmy O. (2003). Zum Gebrauchs-und Tragverhalten von Tunnelschalen aus Stahlfaserbenton und stahfaserverstaerktem Stahlbeton. PHD-thesis, Technischen Universitaet Braunschweig, Braunschweig.

[6] Ding Y., Liu H., Pacheco-Torgal F., Jalali S. (2011): Experimental investigation on the mechanical behaviour of the fiber reinforced high performance concrete tunnel segment, Composite Structures, 93:, 1284-1289.

[7] Falkner H., Henke V. (2004): SFRC - Shear load bearing capacity and tunnel linings, 6th RILEM Symposium on Fiber-Reinforced Concrete (FRC) - BEFIB 2004, 20-22 Sept., Varenna, Italy.

[8] Chiaia B., Fantilli A., Vallini P. (2009): Combining fiber-reinforced concrete with traditional 
reinforcement in tunnel linings, Engineering Structures 31: 1600-1606.

[9] Plizzari G.A., Tiberti G. (2006): Steel fibers as reinforcement for precast tunnel segments, Tunnelling and Underground Space Technology 21: 438-439.

[10] Narayanan R. and Darwish I. (1987): Use of steel fibers as shear reinforcement. ACI Structural Journal 84: 216-227.

[11] Di Prisco M., Plizzari G.A. and Felicetti R.(2004). 6th RILEM Symposium on Fibre Reinforced Concretes (BEFIB 2004). RILEM Publications, Bagneaux (France).

[12] Ashour S. A., Hasanain G. I. S. and Wafa F. (1992): Shear behavior of high-strength fiber reinforced concrete beams. ACI Structural Journal 89: 176-184

[13] Khuntia M., Stojadinovic B. and Goel S. C. (1999): Shear strength of normal and high-strength fiber reinforced concrete beams without stirrups. ACI Structural Journal 96, 282-289.

[14] Mansur M., Ong K. and Paramasivam P. (1986). Shear strength of fibrous concrete beams without stirrups. Journal of Structural Engineering 112: 2066-2079.

[15] Swamy R. N., Jones R., Chiam A. T. P. (1993). Influence of steel fibers on the shear resistance of lightweight concrete I-beams. ACI Structural Journal 90: 103-114

[16] Ding Y., You Zh. and Jalali S. (2011): Composite Effect of Steel Fibres and Stirrups on Shear Behaviour of Beams using Self-Consolidating Concrete, Engineering Structures, 33: $107-117$.

[17] Granju J.-L., Balouch S. U. (2005): Corrosion of steel fibre reinforced concrete from the cracks, Cement and Concrete Research 35: 572- 577.

[18] Japan Society of Civil Engineers (JSCE) (1999). Guidelines of design for RSF piers, 
Concrete library, Vol. 97.

[19] Ken Watanabe, Toshihide Kimura, Junichiro Niwa(2010): Synergetic effect of steel fibers and shear- reinforcing bars on the shear-resistance mechanisms of RC linear members, Construction and Building Materials 24: 2369-2375.

[20] Granju J. L. and Balouch S. U. (2005): Corrosion of steel fibre reinforced concrete from the cracks. Cement and Concrete Research 35, 572-577

[21] Ding Y., Azevedo C., Aguiar J.B., Jalali S. (2012): Study on residual behaviour and flexural toughness of fibre cocktail reinforced self compacting high performance concrete after exposure to high temperature, Construction and Building Materials 26: 21-31.

[22] Ding Y., Zhang Y. and Thomas A. (2009). The Investigation on strength and flexural toughness of fibre cocktail reinforced self-compacting high performance concrete. Construction and Building Materials 23: 448-452.

[23] Gettu R., Barragan B., Garcia T., Ramos G., Fernandez C., Oliver R (2004). Steel fiber reinforced concrete for the Barcelona metro line 9 tunnel lining. In: di Prisco M, et al., editors. 6th RILEM symposium on fibre reinforced concretes. Varenna: RILEM Publications SARL; $141-156$.

[24] Code for design of concrete (2002). GB50010-2002. China Architecture and Building Press Beijing.

[25] RILEM TC 162-TDF (2002). Test and design methods for steel fibre reinforced concrete, Final recommendations, Mater Struct/Materiaux et Construct. Vol. 35. 579-82. 